\title{
Pathogenesis of the impaired gall bladder contraction of coeliac disease
}

\author{
A M BROWN, M J BRADSHAW, R RICHARDSON, J G WHEELER, \\ AND R F HARVEY
}

From the Gastroenterology Unit and Departments of Medicine and Medical Physics, Frenchay Hospital, Bristol

SUMMARY We have investigated the possibility that the abnormally decreased gall bladder contraction after meals in patients with coeliac disease might result in part from an abnormality in the gall bladder response to endogenous cholecystokinetic hormones - for example, cholecystokinin and motilin - rather than solely from decreased secretion of such hormones. Eight patients with untreated coeliac disease and nine controls received intravenous infusions of the pure synthetic cholecystokinin analogue caerulein, 2-16 ng/kg/hour. Gall bladder emptying was measured on a minute-by-minute basis using ${ }^{99 m}$ Tc-HIDA scans. In the patients with coeliac disease, gall bladder emptying was greatly decreased $(34.6 \pm 9.9 \vee 61.5 \pm 7.5 \%$ at 60 minutes, $\mathrm{p}<0 \cdot 02$ ), and a much greater dose of caerulein was needed to initiate gall bladder contraction $(3.80 \pm 1.08 \vee 1.49 \pm 0.56 \mathrm{ng} / \mathrm{kg}, \mathrm{p}<0.02)$. These results suggest that the abnormal gall bladder contraction in coeliac disease is not simply because of impaired release of cholecystokinin. Although mechanical factors secondary to the increased gall bladder size in patients with coeliac disease might to some extent account for the findings, the alternative explanation is that the gall bladder muscle is for some reason resistant to the action of cholecystokinetic agents. A similar phenomenon affecting the pancreas might contribute to the abnormally decreased pancreatic secretion found in coeliac disease.

The peptide hormone cholecystokinin is released from the mucosa of the upper small intestine after meals, and is believed to constitute the major stimulus to postprandial gall bladder emptying, although other peptide hormones, such as motilin, may also play a part.' In patients with coeliac disease there is decreased gall bladder contraction after meals, ${ }^{2-5}$ and pancreatic enzyme secretion is similarly decreased. ${ }^{\circ}$ These factors could conceivably contribute to the malabsorption which is a prominent feature of the condition. Because for a variety of reasons radioimmunoassay and other assay methods for cholecystokinin are unusually difficult, ${ }^{78}$ the exact pathogenesis of the impaired gall bladder emptying after meals in patients with coeliac disease is still uncertain. The most obvious explanation is that there may be insufficient release of cholecystokinin (and

Address for correspondence: Dr R F Harvey, Frenchay Hospital, Bristol BS16 II.E.

Received for publication 15 April 1987. perhaps also other cholecystokinetic agents, such as motilin) from the abnormal small intestinal mucosa. ${ }^{911}$ There certainly appears to be an impaired release of cholecystokinin after meals, ${ }^{3+11}$ yet two observations suggest this is not the only abnormality. Braganza and Howat and later Delamarre et al both reported an impaired response to injections of cholecystokinin, indicating an abnormality at gall bladder level. ${ }^{512}$ In this study, we used a cholescintigraphic method to see whether an impaired responsiveness of the gall bladder to cholecystokinetic agents could be shown in patients with untreated coeliac disease.

\section{Methods}

PATIENTS

Eight adult patients with untreated coeliac disease and nine healthy subjects consented to this study. All patients presented initially with diarrhoea or 
anaemia or both. Coeliac disease was diagnosed by the finding of subtotal villous atrophy on jejunal biopsy, with a satisfactory response to a gluten free diet. In the control volunteers there were no symptoms of gastrointestinal tract disease, and no abnormalities of blood count, erythrocyte morphology, plasma proteins, urea or electrolytes. Occult gall stones were excluded in both groups by using grey scale ultrasonography. Gall bladder emptying was studied using a very precise isotope technique, in which the radioactive compound ${ }^{99 m}$ Tc Hydroxyimino diacetic acid (HIDA) is injected intravenously, and accumulates in the gall bladder after being excreted in the bile. ${ }^{1314}$ Because commercially available preparations of cholecystokinin are either impure or very expensive, we used the pure, synthetic and stable cholecystokinin analogue caerulein as the stimulus to gall bladder emptying. ${ }^{15} 16$

Studies were carried out after an overnight fast, using a gamma camera (IGE 400T Maxicamera) fitted with a high resolution collimator interfaced to a microcomputer system. With the subject in the supine position, $185-370 \mathrm{~Bq} / \mathrm{kg}$ body weight $(=5-10$ $\mu \mathrm{Ci} / \mathrm{kg}$ ) of the imino diacetic acid derivative ${ }^{9{ }^{4 m}} \mathrm{Tc}-$ HIDA were injected intravenously. Serial scintiscan images of one minute duration, centred over the liver and gall bladder, were obtained for the next 160 minutes.

It was invariably found that over $90 \%$ of the isotope had been excreted by the liver and had accumulated in the gall bladder by 75 minutes after the injection. At this time an intravenous infusion of secretin, 0.5 Crick Harper Raper units $/ \mathrm{kg} /$ hour (Boots Pure Drug Co, Nottingham) was started, and this was continued throughout. At 90 minutes an infusion of the cholecystokinin analogue caerulein (a gift from Farmitalia Carlo Erba Ltd), $2 \mathrm{ng} / \mathrm{kg} /$ hour, was started for 15 minutes, followed by a dose of $4 \mathrm{ng} / \mathrm{kg} / \mathrm{hour}$ for a further 15 minutes, then $8 \mathrm{ng} / \mathrm{kg} /$ hour for 15 minutes, and a final dose of $16 \mathrm{ng} / \mathrm{kg} /$ hour for a further 15 minutes (Fig. 1).

The rate of gall bladder emptying was calculated by measuring the rate at which the radioactive ${ }^{{ }^{4 m} \mathrm{Tc}} \mathrm{Tc}$ HIDA left the gall bladder, using the method of Krishnamurthy et al,$^{13}$ with minor modifications to allow for blood and organ background, movements of the subject and isotopic decay. Isotope distribution was recorded by the gamma camera (Figs 2-4), on a minute-by-minute basis, and stored on computer tape for a later analysis.

The emptying of isotope from the gall bladder was measured continuously (Fig. 1), and gall bladder response to the infusion of caerulein was assessed by calculating the time at which emptying began (taken as a fall of $10 \%$ in gall bladder radioactivity), the dose of caerulein required to initiate emptying, the maxi-

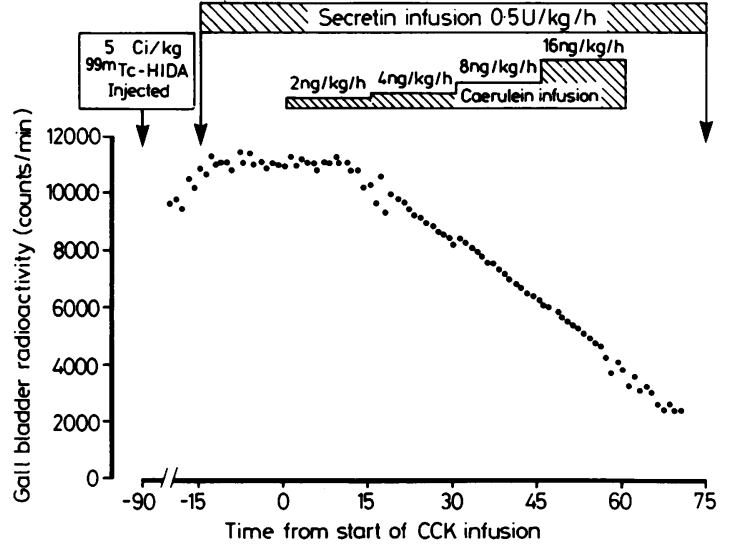

Fig. 1 Example of the effect of intravenous caerulein on gallbladder radioactivity, showing the timing of the different infusions. In this instance, gallbladder emptying begins during the infusion of $2 \mathrm{ng} / \mathrm{kg} / \mathrm{hour}$ of caerulein.

mum emptying rate and the time at which this occurred, and the total percentage emptying by the end of the caerulein infusion.

\section{Results}

Patients with coeliac disease required a considerably larger dose of caerulein to initiate gall bladder emptying $(3.80 \pm 1.08 v 1.49 \pm 0.56 \mathrm{ng} / \mathrm{kg}, \mathrm{p}<0.02)$, and there was a correspondingly longer delay from the start of the infusion until emptying began. The speed of gall bladder emptying tended to be slower than normal in patients with coeliac disease, but this was not statistically significant. By the end of the 60 minute infusion of caerulein, gall bladder emptying was less complete in the patients than in the controls (percentage emptying at end of caerulein infusion $34.6 \pm 9.9 v 61.5 \pm 7.5, \mathrm{p}<0.02)$. A summary of the results is given in the table (Table) and illustrated in Figure 5.

The statistical significance of differences in the various measurements listed in the Table between control subjects and patients with coeliac disease was assessed using Student's $t$ test. All statistically significant differences were checked with the Wilcoxon's signed-rank test, and similar results were obtained.

\section{Discussion}

A number of studies have shown that gall bladder emptying after meals is abnormally decreased in patients with coeliac disease. ${ }^{2-617}$ Using various different forms of assay for cholecystokinin, decreased release of this peptide after meals has also been shown in such patients, ${ }^{3+11}$ and it has been 


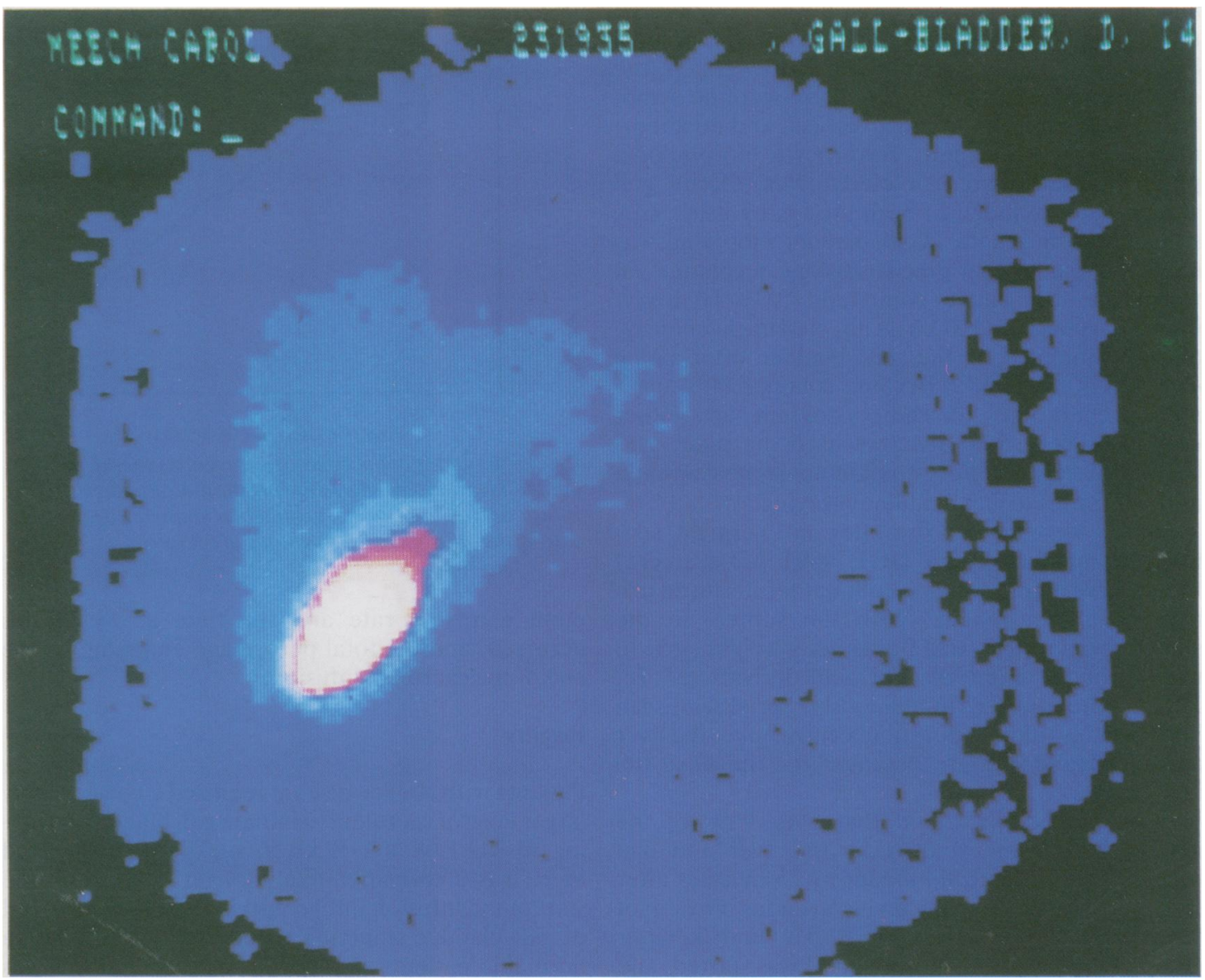

Fig. 2 Gamma-camerascan of abdomen at the start of the study, 75 minutes after injection of ${ }^{* m}$ TC-HIDA. Approximately $90 \%$ of the injected isotope is in the gall bladder (shown as white), with none in the gut and a small amount in the liver.

suggested that this decreased release from the abnormal upper small intestinal mucosa is sufficient to explain the gall bladder abnormality. ${ }^{\text {th }} 1117$ Both Braganza and Howat ${ }^{12}$ and Delamarre et al, ${ }^{5}$ however, have shown that in patients with coeliac disease the gall bladder responds poorly to bolus injections of cholecystokinin, suggesting that the inertia results not only from impaired cholecystokinin release, but also from a reversible abnormality of the gall bladder itself. Our study confirms their observations and suggests that, although the gall bladder is still capable of responding to cholecystokinetic agents, provided a sufficient dose is given, ${ }^{617}$ there is a shift in the dose response curve to the right, in other words a decreased response to submaximal doses of the stimulus. As the abnormality is reversible with a gluten free diet, ${ }^{\prime}$ there is presumably no permanent damage to gall bladder muscle, so it seems most probable that the decreased gall bladder sensitivity is the result of an abnormality at the cholecystokinin receptor site, or of some alteration in the mechanical properties of the gall bladder muscle itself.

Relatively little is known about the CCK receptor in the gall bladder wall, ${ }^{18}$ its mode of action on the gall bladder smooth muscle, or its interactions with other adjacent receptors (although CCK receptors in the acinar cells and in the brain have been studied extensively. ${ }^{19-22}$ Other receptors are present in the gall bladder muscle, notably adrenergic receptors and histamine $\mathrm{H}_{1}$ and $\mathrm{H}_{2}$ receptors, and presumably also receptors for other peptides, such as secretin, pancreatic polypeptide and somatostatin, all of which inhibit the effects of CCK on the gall bladder, and for motilin, which stimulates gall bladder contraction.

One other condition is known in which gall bladder inertia is associated apparently with an abnormal behaviour of the CCK receptor. In pregnancy, and after administration of progestogens, it behaves as it 


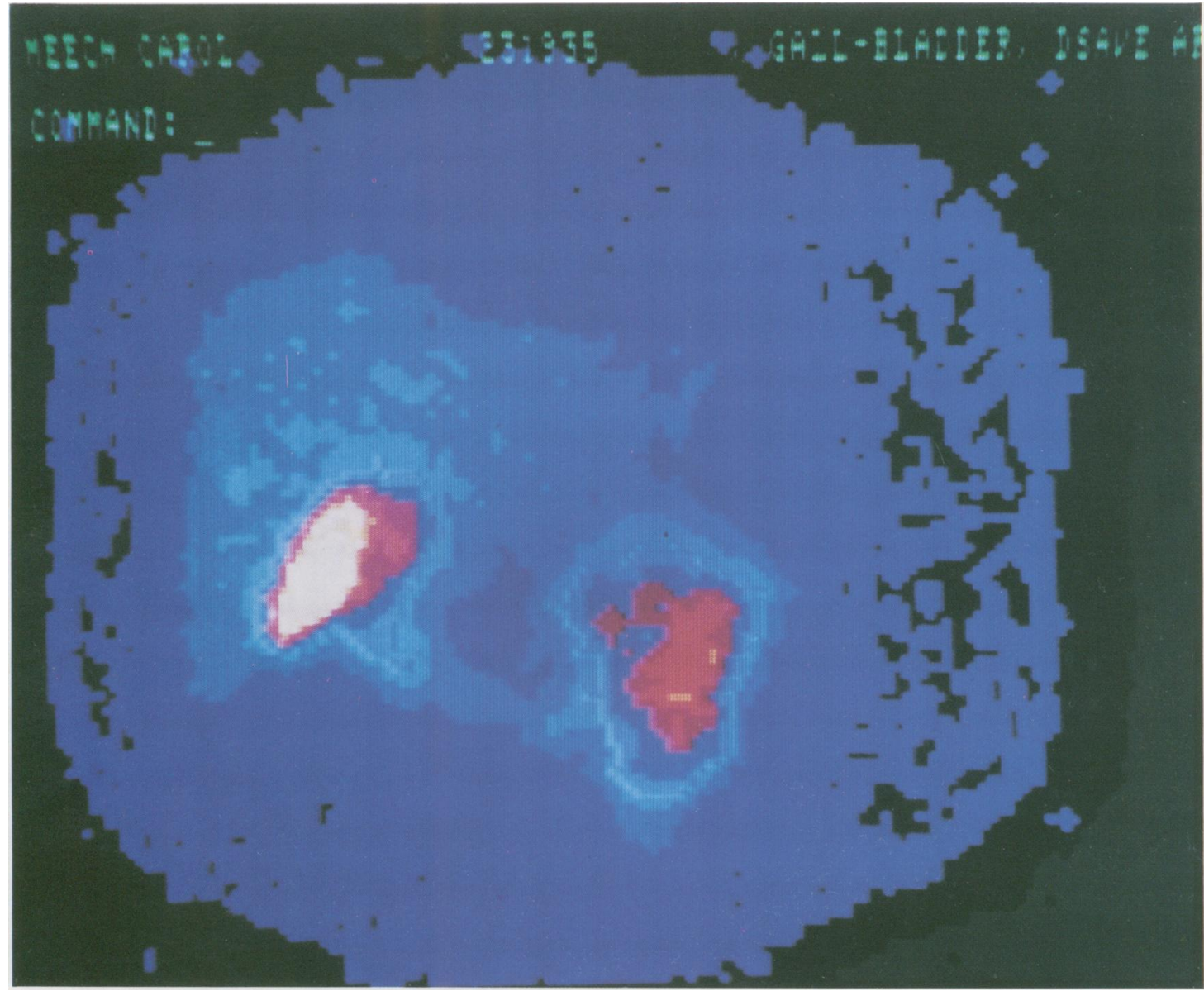

Fig. 3 Scan at 30 minutes from the start of the caerulein infusion. Approximately $25 \%$ of the ${ }^{\text {"xm }}$ TC-HIDA has been expelled from the gall bladder, and is shown in the upper loops of the small intestine.

does in coeliac patients, having a larger resting volume and a decreased response to meals or CCK. ${ }^{2-25}$ In vitro studies with guinea pig gall bladders have shown that the response to direct muscle stimulation (by increased extracellular potassium concentrations) is normal, whereas the response to substances which mediate their action by way of receptors - for example, CCK and acetylcholine, is reduced. ${ }^{25}$

Despite these latter observations, it is still possible that the gall bladder abnormality could simply reflect a mechanical phenomenon resulting from its increased size in coeliac disease. If the gall bladder volume was $30 \%$ greater in some patients, they might expel a similar total volume of bile to that of normal subjects, yet this would not be reflected in the change of gall bladder radioactivity, which shows emptying as a proportion of original gall bladder volume rather than as an absolute volume change. A similar theory could be used to explain the greater threshold dose of caerulein required to initiate emptying. In order to generate enough intraluminal pressure to empty the gall bladder, the gall bladder muscle must shorten by a certain length. Because the muscle fibres are presumably larger in the dilated gall bladder of coeliac patients, they must shorten more in order to initiate emptying. Hence a larger amount of caerulein (or CCK) might be required. This theory could be tested relatively easily by carrying out similar studies to this one but using volumemeasuring techniques such as ultrasonography to assess gall bladder volume changes directly.

If the abnormality lay at the receptor site level, there are various factors which might influence the responsiveness of the gall bladder CCK receptor to cholecystokinin (or to analogues such as caerulein). There might, for some reason, be a decrease in the number of receptors, ${ }^{21}$ or else one of two types of 


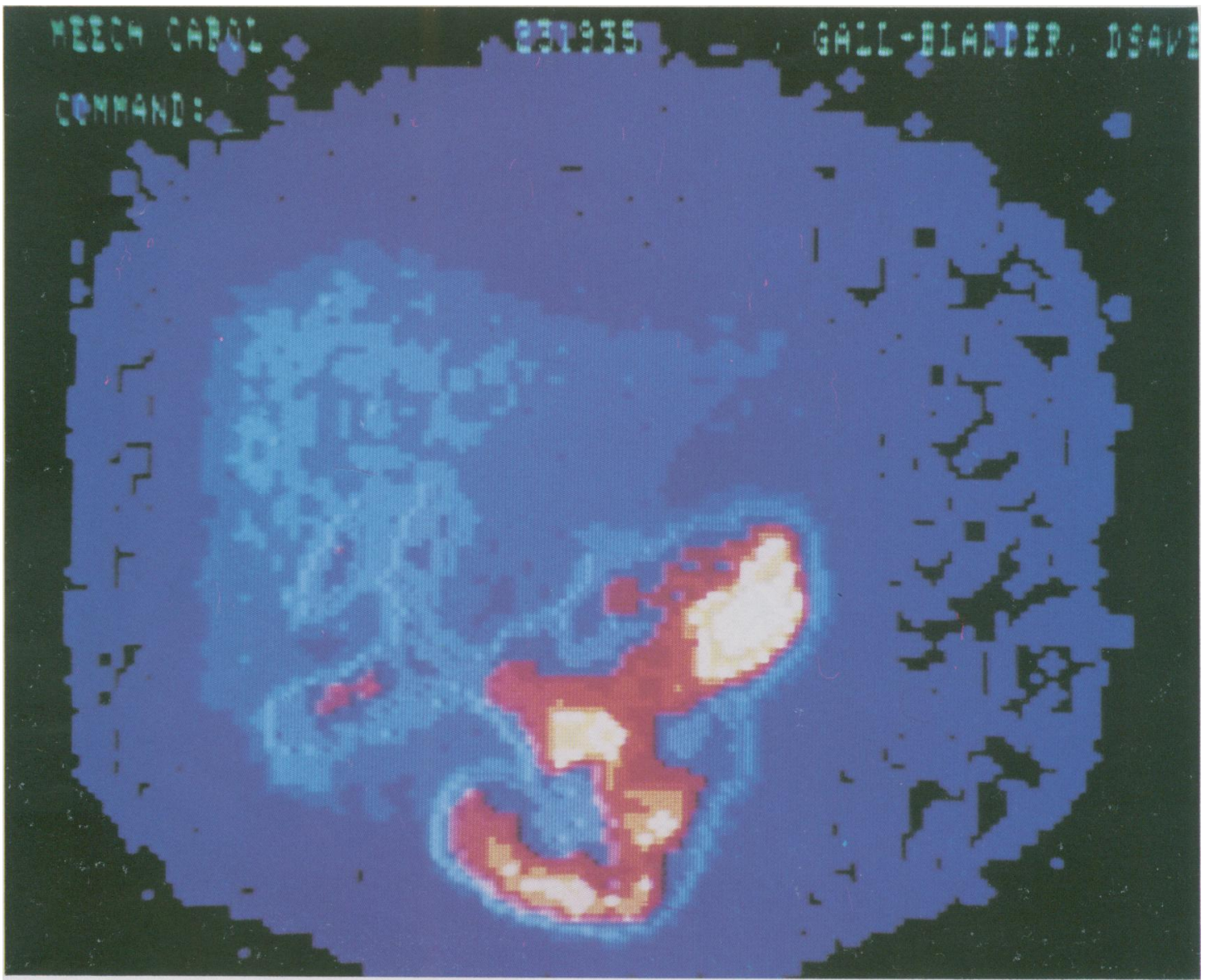

Fig. 4 Scan at 60 minutes from the start of the caerulein infusion. Approximately $85 \%$ of the ${ }^{1 m} T c-H I D A$ is now in the small intestine, with very little remaining in the gall bladder.

inhibition, competitive or non-competitive. A competitive antagonist (for example a biologically less active form of $\mathrm{CCK}^{26}$ or various chemically unrelated inhibitors ${ }^{27}$ should have its effect overcome if sufficient CCK is given. A non-competitive inhibitor, in contrast, acts at a separate site, and is associated with a decreased maximum response and a normal $D_{50}$ (the dose required to produce $50 \%$ of the maximum observed effect). Either type of inhibition could have produced the results found in the present study.

In the study of Low-Beer $e a^{+}$which used a very sensitive radioimmunassay for cholecystokinin, ${ }^{29}$ fasting concentrations of CCK were found to be abnormally raised in patients with coeliac disease, although the rise in response to a meal was abnormally low. This puzzling finding has not been confirmed by any other study, but this may be because in the only two reports which have been published up to the present time, the sensitivity of the assays used was not sufficient to detect fasting plasma concentrations of $\mathrm{CCK}$ in either normal subjects or patients with coeliac disease. ${ }^{+11}$ Alternatively this may have been an anomalous result of some sort of assay artefact, as no two centres using CCK radioimmunoassay techniques seem able to agree on their methods or results. The number of CCK secreting endocrine cells in the small intestinal mucosa of patients with coeliac disease is abnormally increased. ${ }^{31.31}$ Such hyperplasia of CCK cells would be consistent with increased basal secretion of CCK in coeliac disease, similar to the hyperplasia of gastrin secreting cells in the antrum of patients with achlorhydria and hypergastrinaemia. Whether in fact this does occur, and if so, what mechanisms are involved, must await further studies. The possible relevance to the current study is that the effect of constant low level stimulation of the CCK receptor by increased basal CCK concentrations 
Table Differences in gallbladder emptying between control subjects and patients

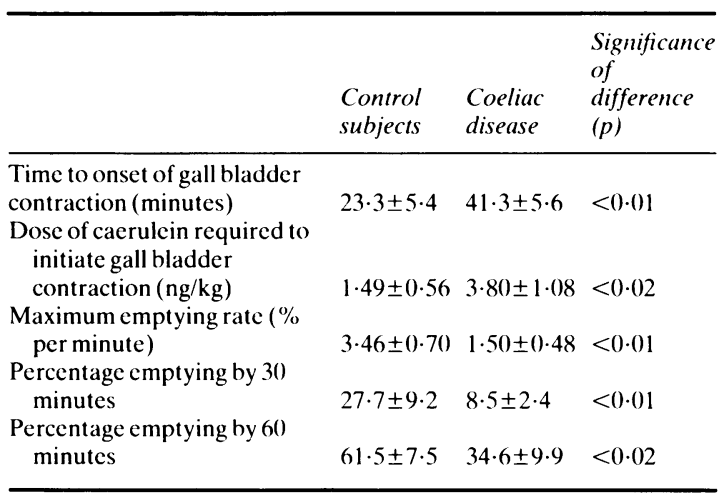

might be to decrease sensitivity of the CCK receptor by 'fade' or tachyphylaxis. ${ }^{3}$

Another possible explanation for the gall bladder abnormality in coeliac disease is that the abnormal small intestinal mucosa is actively secreting a noncompetitive inhibitor of cholecystokinetic agents. Sjolund $e \mathrm{al}^{31}$ showed increased numbers of somatostatin, GIP and glucagon cells in coeliac mucosa, and each of these peptides can inhibit the effects of CCK. Various non-peptide inhibitors of the action of CCK are also known. ${ }^{27.32}$ Using bioassay methods, ${ }^{3.3}$ it should be possible to look for an inhibitor of the action of CCK in plasma from patients with coeliac disease and gall bladder inertia.

Finally, it is possible that gall bladder contraction in coeliac disease might be inhibited by a nervous mechanism. Reflexes from the upper gastrointestinal tract to the gall bladder have been described, ${ }^{31}$ but relatively little is known about them. Contrary to current opinion, however, the action of CCK on the gall bladder is to some extent dependent on nervous

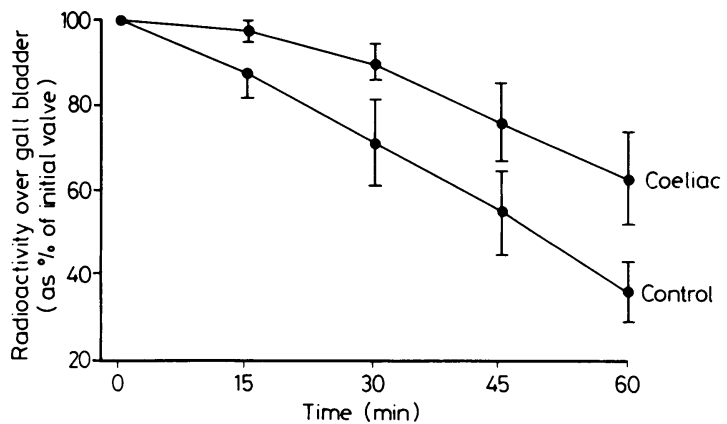

Fig. 5 Gall bladder emptying in patients with coeliac disease and in control subjects. The degree of emptying in patients with coeliac disease is significantly less than normal at 30,45 , and 60 minutes. influences, as can be shown by the inhibitory effect of atropine on CCK induced gall bladder contraction. ."

If patients with coeliac disease have a circulating inhibitor of the effect of CCK, then it might well act on the pancreas as well as the gall bladder, as the intracellular consequences of CCK acting on its receptor are similar in the two organs. ${ }^{37} \mathrm{~A}$ decreased response of the pancreas to intraduodenal amino acids has been reported in coeliac disease, and was originally interpreted as being solely because of impaired CCK release, as injection of large doses of CCK produced normal enzyme secretion in these patients. "Later studies have shown, however, that if smaller doses of CCK are injected, abnormally decreased pancreatic enzyme secretion can be shown in many patients with coeliac disease. ${ }^{31 \text { it }}$ If this is indeed the case, it makes the 'mechanical' explanation of our findings - that is, that they result simply from increased gall bladder size, rather less likely. It is more probable that whatever is affecting the gall bladder response to $\mathrm{CCK}$ is also affecting the response of the pancreas, where presumably a similar list of possible explanations as to the exact mechanism of this finding applies.

Thus patients with coeliac disease have not only to contend with a damaged small intestinal mucosa, but their malabsorption may possibly be increased by faulty gall bladder contraction and reduced pancreatic enzyme secretion. The degree of abnormality in gall bladder response to injected CCK found in this study suggests that this contributes considerably to the decreased gall bladder contraction after meals seen in patients with coeliac disease.

This study is based on a communication given to the British Society of Gastroenterology in March 1985 , and published in abstract form (Gut 1985; 26: A580) A581). We are grateful to Dr Helen Sussman and Farmitalia Carlo Erba for supplies of caerulein; to Philip Smith and Dr Clare Morris for help with the computer programming; to the patients and volunteers who took part in the study; to the Bristol friends of the British Digestive Foundation for financial support, and to Judy Seward for help with the manuscript.

\section{References}

1 Jorpes JE, Mutt V. Secretin and cholecystokinin (CCK). In: Jorpes JE, Mutt V, eds. Handbook of experimental pharmacology. Vol 34: Secretin, cholecystokinin, pancreozymin and gastrin. Berlin: SpringerVerlag, 1973: 1-179.

2 Low-Beer TS, Heaton KW, Heaton ST, Read AE. Gallbladder inertia and sluggish enterohepatic circulation of bile-salts in coeliac disease. Lancet 1971; i: 991-4.

3 Low-Beer TS, Harvey RF, Davies ER, Read AE. Abnormalities of serum cholecystokinin and gallbladder 
emptying in coeliac disease. $N$ Engl J Med 1975; 292: 961-3.

4 Maton PN, Selden AC, Fitzpatrick ML, Chadwick VS. Defective gallbladder emptying and cholecystokinin release in coeliac disease. Reversal by gluten-free diet. Gastroenterology 1985; 88: 391-6.

5 Delamarre J, Capron JP, Joly JP, et al. Atonie vesiculaire et maladie coeliaque de l'adulte. $J$ Radiol (Paris) 1984; 65: 133-6.

6 Dimagno EP, Go VLW, Summerskill WHJ. Impaired cholecystokinin-pancreozymin secretion, intraluminal dilution and maldigestion of fat in sprue. Gastroenterology 1972; 63: 25-32.

7 Harvey RF. Cholecystokinin-pancreozymin. In: Jaffe BM, Behrman HR, eds. Methods of hormone radioimmunoassay. New York: Academic Press, 1979: 495-526.

8 Rehfeld JF. How to measure cholecystokinin in plasma. Gastroenterology 1984; 87: 434-8.

9 Besterman HS, Bloom SR, Sarson DL, et al. Gut hormone profile in coeliac disease. Lancet 1978; i: 785-88.

10 Bloom SR, Polak JM. Plasma hormone concentrations in gastrointestinal disease. In: Creutzfeldt W, ed. Gastrointestinal hormones. Clinics in Gastroenterology 1980; 9: 785-98.

11 Calam J, Ellis A, Dockray GJ. Identification and measurement of molecular variants of cholecystokinin in duodenal mucosa and plasma. Diminished concentrations in patients with coeliac disease. J Clin Invest 1982; 69: $218-25$.

12 Braganza J, Howat JT. Gallbladder inertia in coeliac disease. Lancet 1971; i: 1133.

13 Krishnamurthy GT, Bobba VR, Kingston E. Radionuclide ejection fraction: a technique for quantitative analysis of motor function of the human gallbladder. Gastroenterology 1981; 80: 482-90.

14 London JW, Greenberg A, Alavi A, Goldstein HA. Automated calculation of gallbladder ejection fraction. Eur J Nucl Med 1983; 8: 307-11.

15 Anastasi A, Erspamer V, Endean R. Isolation and structure of caerulein, an active decapeptide from the skin of Hyla caerulen. Experientia 1967; 23: 700-2.

16 Bertaccini G, de Caro G, Endean R, Erspamer V, Impicciatore $\mathrm{M}$. The actions of caerulein on the smooth muscle of the gastrointestinal tract and gallbladder. $\mathrm{Br} J$ Pharmacol 1968; 84: 291-310.

17 Colombato LO, Parodi H, Cantor D. Biliary function studies in patients with coeliac sprue. Am J Dig Dis 1977; 22: 96-8.

18 Steigerwalt RW, Goldfine ID, Williams JA. Characterisation of cholecystokinin receptors on bovine gallbladder membranes. Am J Physiol 1984; 247: G709-14.

19 Innis RB, Snyder SH. Distinct cholecystokinin receptors in brain and pancreas. Proc Natl Acad Sci USA 1980; 77: 6917-21.

20) McLaughlin CL, Peikin SR, Baile CA. Decreased pancreatic CCK receptor binding and CCK-stimulated amylase release in Zucker obese rats. Physiol Behav 1984; 32: 961-5.

21 Wennogle LP, Steel DJ, Petrack B. Characterisation of central cholecystokinin receptors using a radioiodinated octapeptide probe. Life Sci 1985; 36: 1485-92.

22 Fujimoto $\mathrm{M}$, Igano K, Watanabe K, Irie I, Inovye K, Okabayashi T. Effects of caerulein-related peptides on cholecystokinin receptor bindings in brain and pancreas. Biochem Pharmacol 1985; 34: 1103-7.

23 Braverman DJ, Johnson ML, Kern F Jr. Effects of pregnancy and contraceptive steroids on gallbladder function. N Engl J Med 1980; 302: 362-4.

24 Everson GT, McKinley C, Lauson M, Johnson M, Kern F Jr. Gallbladder function in the human female: effect of ovulatory cycle, pregnancy and contraceptive steroids. Gastroenterology 1982; 82: 711-9.

25 Ryan JP. The effect of pregnancy on gallbladder contractility in the guineapig. Gastroenterology 1984; 87: 674-8.

26 Spanarkel M, Martinez J, Briet C, et al. CCK-27-32amide. J Biol Chem 1983; 256: 6746-9.

27 Gardner JD, Jensen RT. Cholecystokinin receptor antagonists. Am J Physiol 1984; 246: G471-6.

28 Jensen RT, Murphy RB, Trampota M, et al. Proglumide analogues: potent cholecystokinin receptor antagonists. Am J Physiol 1985; 249: G214-20.

29 Harvey RF, Dowsett L, Hartog M, Read AE. Radioimmunoassay of cholecystokinin-pancreozymin. Gut 1974; 15: 690-9.

30 Polak JM, Bloom SR, McCrossman CM. Cholecystokinin abnormalities in coeliac disease. Gastroenterology 1978; 74: 1097.

31 Sjolund K, Alumets J, Berg NO, et al. Duodenal endocrine cells in adult coeliac disease. Gut 1979; 20: 547-52.

32 Haline WF, Jensen RT, Lemp GF, et al. Proglumide and benzotript: members of a different class of cholecystokinin receptor antagonists. Proc Natl Acad Sci USA 1981; 78: 6304-8

33 Johnson AG, McDermott S. Sensitive bioassay of cholecystokinin in human serum. Lancet 1973; 2: 589-91.

34 Debas HT, Yamagishi T. Evidence for a pylorocholecystic reflex for gallbladder contraction. Ann Surg 1979; 190: 170-5.

35 Gollo L, Bolondi L, Priori P, Cassanova P, Labo G. Inhibitory effect of atropine on cholecystokinin-induced gallbladder contraction in man. Digestion 1984; 29: 209-13.

36 Amer MS. Cyclic guanosine 3' 5' monophosphate and gallbladder contraction. Gastroenterology 1974; 67: 333-7.

37 Albano J, Bhoola KD, Harvey RF. Intracellular messenger role of cyclic GMP in exocrine pancreas. Nature 1976; 262: 404-6.

38 Zieve L, Silvis SE, Mulford B, et al. Secretion of pancreatic enzymes. 1 Response to secretin and pancreozymin. Am J Dig Dis 1966; 11: 671-84.

39 Herskovic T. The exocrine pancreas in intestinal malabsorption syndromes. Am J Clin Nutr 1968; 21: 520-2.

40 Novis BH, Banks S, Marks IN. Exocrine pancreatic function in intestinal malabsorption and small bowel disease. Am J Dig Dis 1972; 17: 489-94.

41 Regan PR, Di Magno EP. Exocrine pancreatic insufficiency in coeliac sprue: a cause for treatment failure. Gastroenterology 1980; 78: 484-7. 